\title{
23 \\ FROM GRASS ROOTS TO GOVERNMENT
}

\section{The Role of Social Connections and Integrated Policy Responses to Support Our Path to Health in a Sustainable World}

\author{
KATHRYN BOWEN
}

\section{Abstract}

Strong action on climate change is moving at a very slow pace globally. Are workers in the field really making a worthwhile difference to the health issues brought about by climate change? If we are not, what are the reasons for this lack of progress and how do we better address the impact of climate change on both local and global health issues? This chapter shifts from outlining the problems with the lack of action on climate and health to proposing ways by which we can galvanise attention and promote appropriate action. We can progress action on climate change and reducing its ill effects on human health by using a two-pronged approach: (i) by highlighting and encouraging basic human positive attributes, such as being connected with one's community and recognising the finite nature of our resources; and (ii) by framing health and sustainability as an integral part of poverty-reduction strategies and national development plans. These two mechanisms may provide an approach by which we can synergise broader-based support by communities for meaningful action on the promotion of sustainability and the development of an active ongoing working partnership with grass-roots groups as well as national- and international-level organisations. 


\section{Introduction}

I first came across Professor McMichael's work when I was assisting the Australian Greens develop their climate change and human health policy in the run-up to a federal election. I was at an intersection in my public health career; I felt that my choices were either to continue working on specific public health issues such as HIV, mental health and women's health, or to follow my instinct to move away from public health and work in the environmental sustainability arena. On coming across Tony's work, I realised that public health and sustainability dovetailed in a very powerful way. I was inspired by what Tony was doing. His passion for his work was clear in his writing, and this encouraged me to consider the possibility of combining both public health and sustainability, which was incredibly exciting. This brief chapter reminds us of some basic solutions that may contribute to supporting and respecting our natural environment, with clear positive repercussions for us as humans.

\section{Two Approaches and Two Solutions}

Plenty of evidence pointing to environmental change, and the impact this has on global health, has been articulated by other authors in this book. Thus, this chapter expands on ways, such as the support of social connectedness and cooperation, that can propel our efforts to actually change the way that we, as humans, support our Earth. And this, in turn, may mean that the Earth might be able to continue to support us. This thinking is in line with the Gaia theory. The first solution that I propose is the importance of encouraging basic positive human attributes, such as being connected with one's community and recognising the finite nature of our resources. The second solution that I propose is a strategic approach by which we can address global environmental change (particularly climate change) in the most vulnerable populations, which is often in developing contexts. This entails the linking of climate change activities and funding with national policies, including health policies, National Development Plans (NDPs), disaster reduction policies and Poverty Reduction Strategy Papers (PRSPs).

A recent straw poll carried out in early 2013 by The Guardian newspaper in the UK asked 50 readers and public figures to indicate ways by which we might extricate ourselves from the dire predicament brought about by an impending global warming of more than $2^{\circ}$ Celsius. While all of the solutions proposed made sense in terms of making a change that benefitted the planet, many were just too unrealistic to be useful, such as fomenting mass protest (which has not mobilised any change to this point), mobilising as if on a war footing 
(requires impetus from within government) and ending lobbyists' influence on government (again requiring government cooperation and will to act, both of which are currently sorely lacking). The theme that came through most often in the 50 responses was the importance of building community resilience, commonly through measures that increased social capital, such as knowing your neighbours and pulling together on shared tasks. This is a commendable and potentially feasible option; the question now is what is the best way to go about doing this. Should it be mandated by government or should the impetus come from the grass roots? Or, is it indeed an 'either/or' scenario?

\section{Social Connectivity}

The ability to withstand the gathering stresses from global environmental changes requires a combination of physical, financial and intellectual resources and preparedness. It also requires strong social cohesion, social connectedness and human cooperation. These unifying forces are commonly referred to as social capital. I suggest that a prerequisite for establishing sufficient social capital to protect both our immediate environment and our planet as a whole is to actively promote an increasing respect for the natural environment.

The importance of developing an increased respect for the natural environment is illustrated by research connecting children with their natural environment. The more exposure children of a young age have to their natural environment (parks, reserves, bush, beach, lakes and so on), the greater their appreciation and understanding of the need to protect and preserve these environments (Sobel, 1990).

The perceived lack of children's connection to nature has resulted in the formation of various groups that seek to re-establish this link. These began in the USA, and have also recently commenced in at least one city in Australia. It is somewhat ironic that extolling the virtues of connecting a child with nature nowadays seems to require structured sessions in a controlled and somewhat artificial environment. The existence of these groups highlights the emerging reality that children's engagement and enthusiasm for the natural environment does not seem to occur quite as spontaneously as before the advent of the electronic age; children now seem much more connected to electronic devices than to each other and their natural environment.

The husbanding of social capital needs to operate in tandem with the establishment of a connection to nature to help preserve and sustain our natural environment. The concept of social capital is rooted in antiquity, but usage of the term is recent (Putnam, 1995). Despite competing definitions of the term, there is general agreement that it can be considered as the capacity 
of a population to work harmoniously as a self-organising unit, in which many individuals cooperate but in which no single person, or even group, controls all activities. Instead of having control imposed from the top down, self-organising groups generally function well because participants both apply and acquire norms and customs that inform and influence behaviour from their milieu; their parents, families, schools, the media and, more recently, from a plethora of informed correspondents on Internet blogs (e.g. Rough, 1996). Two of the chief protagonists often cited in the social capital literature - Putnam and Bourdieu - display differences in their conceptual approaches to social capital (e.g. Bourdieu, 1986; Putnam, 1995). One main difference between the two is Bourdieu's emphasis on individual connections that foster greater connectivity between these individuals versus Putnam's approach on connectivity that has benefits on a broader scale, such as within communities as a whole (Portes, 1998).

In relation to this greater emphasis on communities that Putnam adopts, the quality of the social capital within a community has been suggested as a measure of its potential for adopting a cooperative approach to addressing local problems (Fukuyama, 2001; Pilkington, 2002). Groups with lower amounts of social capital are likely to exhibit a lower degree of trust between members of the group. Communication is likely to be impeded, due to factors such as differences in language, dialect, tone of speech and even nuances of body language. Trade is also likely to be less efficient, due, for example, to an increased need for mediators and agents, such as lawyers and contracts. Weak controls on individuals or groups who attempt to appropriate a share of produce which is disproportionate to their contribution) can reduce the morale and productivity of those individuals and groups who are highly motivated to build community cohesiveness (Ohtsuki et al., 2009).

Cohesive societies are more likely to be able to build and retain the many other forms of wealth (Arrow et al., 2004) that contribute to human well-being (Butler et al., 2003). Such societies are also more likely to respond to and withstand pressures that threaten well-being, including global environmental change (such as climate change). Of course, social cohesion alone does not provide a simple solution for increasing the overall wealth of a community; this also requires access to other forms of capital and raw material, especially environmental resources, appropriate financing and technological knowledge. In this way, social capital should not be seen as an unreservedly positive concept, but rather as a key ingredient in a recipe that must also consider issues including broader socio-economic reform (Tittensor, 2007).

Despite such reservations about the concept of social capital and the importance of understanding the broader policy settings, there is a growing interest in social capital and its potential impact for affecting collective action. This is particularly evident in research into sustainable renewable natural resource 
institutions (Rudd, 2000; Sobels et al., 2001; Walters, 2002; Adger, 2003). For example, Pretty and Ward (2001) identified that where social capital was well developed, local groups with locally developed rules and sanctions were able to make more of existing resources than individuals working alone or in competition. Social institutions that are based on trust and reciprocity and agreed norms and rules for behaviour can mediate private action such as overuse and underinvestment in natural capital (Pretty and Ward, 2001).

Adger (2003) notes that benefits accrue out of building trust and cooperation between the state, its bureaucracy and wider society when addressing the issue of climate change adaptation. One is that there is a useful synergism to be gained from an alliance of community social capital and inclusive decision-making institutions to promote the sustainability and legitimacy of any adaptation strategy. The second is that adaptation processes that are community initiated and based on social capital can shift the perception of climate change from being an insoluble global problem to that of a local problem that may, in fact, be at least partially solvable.

Alongside strengthening community connectivity sits the second suggested solution to increasing our pace of change to prevent further environmental degradation and to improve population health simultaneously. This solution needs only a short explanation. It does not rely on or introduce theory, nor is it particularly controversial. It is more specifically around supporting health in this era of climate change, but with an awareness of the co-benefits of action (both mitigation and adaptation) on both environmental and health outcomes. It is proposed that health and sustainability issues are framed as an integral part of (i) health policies; (ii) disaster reduction policies; (iii) poverty reduction strategies; and (iv) NDPs. The latter two types are common to least-developed countries. All these policies and plans are often developed in isolation from one another, but this is particularly the case for health policies. It is vital that the aims of health policies are integrated into the others, as this will force the understanding of health impacts that are as a result of global environmental change. Progress is being made to integrate these policies with each other, as often this integration is demanded by donors in order for activities to be funded. Additional regulation would further support this progress. Learning from the lessons of the Health in All Policies (HiAP) process and outcomes would also be useful here, as one way to assist the strengthening of a holistic approach to health, development and sustainability policies. HiAP incorporates health impacts into the policy development processes of all sectors and government agencies, creating an integrated policy response across the whole of government (Kickbusch, 2008). This approach is generally regarded as a useful and important step towards improving health equity and is being implemented in many settings, including Australia (South Australia) (Kickbusch, 2008). 


\section{Conclusion}

In conclusion, there are at least two means by which we can support our efforts to protect our natural environment while supporting our human health; by encouraging (i) the social connections that can spur on individual and hence community action, as well as (ii) ensuring environmental change issues and their health impacts are considered in an integrated manner across more segments of government policy. If we can focus on these two elements of grass-roots and government change, we can hopefully see some quicker, and lasting, progress.

\section{References}

Adger, N.W. 2003. Social capital, collective action, and adaptation to climate change. Economic Geography 79, 387-404.

Arrow, K., Dasgupta, P., Goulder, L., Daily, G., Ehrlich, P., Heal, G., et al. 2004. Are we consuming too much? Journal of Economic Perspectives 18, 147-72.

Bourdieu, P. The forms of capital. In: John G. Richardson (ed.): Handbook of Theory and Research for the Sociology of Education. New York: Greenwood Press 1986, 241-258.

Butler, C.D., Chambers, R., Chopra, K., Dasgupta, P., Duraiappah, A., Kumar, P., et al. 2003. Ecosystems and Human Well-being. A Framework for Assessment. Millennium Ecosystem Assessment. Island Press, Washington, DC, USA, 7184.

Fukuyama, F. 2001. Social capital, civil society and development. Third World Quarterly 22, 7-20.

Kickbusch, I. 2008. Healthy Societies: Addressing 21st Century Health Challenges. Department of Premier and Cabinet, Adelaide, SA, Australia.

Ohtsuki, H., Iwasa, Y. \& Nowak, M.A. 2009. Indirect reciprocity provides only a narrow margin of efficiency for costly punishment. Nature 457, 79-82.

Pilkington, P. 2002. Social capital and health: measuring and understanding social capital at a local level could help to tackle health inequalities more effectively. Journal of Public Health 22, 7-20.

Portes, A. 1998. Social capital: its origins and applications in modern sociology. Annual Review of Sociology 24, 1-24. 
Pretty, J. \& Ward, H. 2001. Social capital and the environment. World Development 29, 209-227.

Putnam, R.D. 1995. Bowling alone: America's declining social capital. Journal of Democracy 6, 65-78.

Rough, J. 1996. The Wisdom Council and responsible leadership. Journal for Quality and Participation 19, 74-9.

Rudd, M.A. 2000. Live long and prosper: collective action, social capital and social vision. Ecological Economics 34, 131-44.

Sobel, D. 1990. A place in the world: adults' memories of childhood's special places. Children's Environments Quarterly 7, 5-12.

Sobels, J., Curtis, A. \& Stewart, L. 2001. The role of Landcare group networks in rural Australia: exploring the contribution of social capital. Journal of Rural Studies 17, 265-76.

Tittensor, D. 2007. Social capital and public policy - the current challenge facing the Victorian government. The Australian Journal of Public Administration $66,512-8$.

Walters, W. 2002. Social capital and political sociology: re-imagining politics? Sociology 36, 377-97. 
This text is taken from Health of People, Places And Planet:

Reflections based on Tony McMichael's four decades of contribution to epidemiological understanding, edited by Colin D. Butler, Jane Dixon and Anthony G. Capon, published 2015 by ANU Press, The Australian National University, Canberra, Australia. 